\title{
Hoy y siempre, TÚ eres la primera línea. Alerta Coronavirus (COVID-19) ${ }^{1}$
}

\section{Realizada por Esther Sánchez Gutiérrez ${ }^{2}$}

El profesional de la salud mental -psicoanalista o no- tiene que escapar de las líneas sutiles del positivismo y la tecnologización deshumanizada y socialmente descontextualizada, procurando en cambio la constante clarificación del sentido de lo individual, como producto y agente de lo comunitario.

Colectivo GRITA (2013: 596)

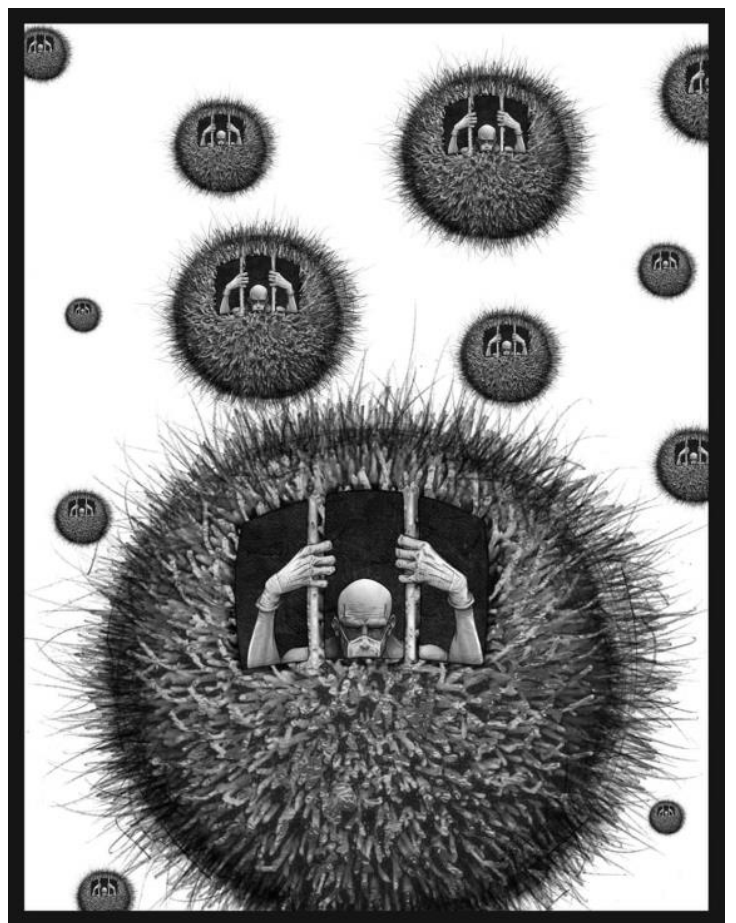

Imagen: Ilustración de "Al Margen"

A raíz del brote pandémico ocasionado por el COVID-19, el gobierno de nuestro País declaró un estado de alarma el pasado 14 de marzo por el que la población se mantiene enclaustrada hasta nueva orden. Algunos en sus hogares y otros en simples domicilios, "positivos" en cuarentena, y en general, todos confinados como medida de prevención. "¡Se paró el mundo!" El tan ansiado y anhelado "me bajo de la vida" atracó en nuestra vida y, sin embargo, a muchos les aprisionó y les derribó como una apisonadora. Y es que, antes de que una pandemia azotara nuestras vidas, existían diversas fórmulas de escape y distracción que permitían automatizar el piloto que nos guía a base de "meter horas" y dar ese 100\% que

\footnotetext{
${ }^{1}$ Sánchez Gutiérrez, E. (2020). Hoy y siempre, TÚ eres la primera línea. Alerta Coronavirus (COVID-19). Clínica e Investigación Relacional, 14 (1): 250-254. [ISSN 1988-2939] [Recuperado de www.ceir.info ] DOI: 10.21110/19882939.2020.140117

${ }^{2}$ Psicóloga. Dirección de contacto: info@esthersanchezpsicologia.com
} 
tanto nos dignifica. Actividades profesionales, culturales, educativas, sociales, deportivas y lúdicas conforman este amplio repertorio de supuestas necesidades y obligaciones, a las que debemos de aspirar con vehemencia por aquello de sentirnos vivos y amortiguar cualquier atisbo de dolencia y malestar.

Ahora deberíamos sentirnos más identificados que nunca, puesto que nos toca experimentar y afrontar una situación que, además de ser inédita, resulta ser genérica, lo que en un principio alentaría a compartir experiencias y pedir ayuda frente a otro tipo de situaciones personales traumáticas sufridas en silencio. Pero el silencio continúa. Mientras persiste el confinamiento, cada uno sobrevive como quiere y/o como puede. Ahora se nos insta a neutralizar la angustia que la cancelación de nuestra cotidianidad y la incertidumbre provocan, intentando armar un escenario dentro de casa que procure simular una aparente normalidad, centrada en el "aquí y ahora", cuando, precisamente, el enemigo ya estaba conviviendo con nosotros. Pensemos en nuestro día a día, y en cómo muchos de nosotros nos vemos expuestos a confrontary, en muchos casos, a sortear: miedos, fobias, obsesiones, compulsiones, ansiedad, alteraciones del estado del ánimo, adicciones, dinámicas de maltrato y violencia, conflictos relacionales, patologías y psicopatologías graves y/o crónicas... Es que, acaso, ¿este tipo de situaciones las ha provocado el coronavirus o es que el virus nos recuerda el lugar infestado e intoxicado que, tantas veces, ocupamos en nuestras vidas? ¿Hay lugar para las distintas subjetividades?

Presenciar y experimentar circunstancias vitales de alto impacto traumático y otras que, en apariencia, tienen una presencia más nimia, implica estar expuesto y responder a modificaciones precipitadas y automatizadas con una importante carga negativa. Modificaciones que deben integrarse e intercalarse junto con el amplio elenco disponible de cogniciones, afectos, conductas y dinámicas. Todo esto, a su vez, genera rupturas e interferencias y la consiguiente sensación de pérdida de control y voluntad a la hora de poder poner en marcha un plan de gestión y afrontamiento ajustado. Así mismo, dependiendo de cómo estén constituidas las fuentes de las que nos estemos nutriendo, tanto desde el propio diálogo interno como del externo, dependerá el reconstruir un posible concepto, más o menos amenazante y persecutorio, de nosotros mismos y de nuestro entorno.

Pensemos que este tipo de situaciones suelen ir acompañadas de una importante sobrecarga de estrés y tensión de compleja canalización e incompatibilidad para continuar atendiendo y conviviendo con las distintas partes que conforman nuestro ser y los roles que ejercitamos. El discurso queda interrumpido, junto con nuestras creencias, ideologías y rutinas. Por este motivo, el evento y sus consecuencias deben contemplarse, no como un hecho aislado y al margen de la posición que mantenga cada persona, sino como una cadena de circunstancias expresa. Este material es para uso científico y profesional exclusivamente y puede contener información clínica sensible. Los editores no se responsabilizan de los contenidos de los autores. Dirigir las consultas sobre derechos y autorizaciones a ceir@psicoterapiarelacional.es 
que se retroalimentan con otros aspectos que definen las condiciones previas en las que se encuadra o enmarca esa persona. La relevancia y significación de estas consecuencias no sólo debe ser explorada desde la supuesta causa directa e inmediata, sino también en cómo un modo de afectación se mezcla con nuestra propia singularidad y subjetividad, nuestra particular idiosincrasia.

¿Cuándo decimos que un acontecimiento es traumático? Sabemos que, frente a un mismo acontecimiento objetivo, cada persona responde de manera distinta, y por ende, al efecto dañino y al propio sufrimiento que se generan en tales circunstancias. La etiqueta de drama, catástrofe o fatalidad que acuñemos a la experiencia va a depender de factores múltiples.

Valorar cómo se estructura y se sostiene la propia identidad, teniendo en cuenta que la construcción de nuestra personalidad y el entorno en que nos hemos criado, configura nuestra particular forma de traumatizarnos, ya que otorgamos un simbolismo e interpretación de lo traumático diferente. Y por supuesto, examinar la respuesta del entorno, ya que podría contribuir negativamente al empeoramiento de la situación desde la invalidación.

Ser conscientes de la influencia de estos factores nos debería hacer reflexionar sobre el hecho de que, para poder comprender y proceder de forma adecuada, deberíamos mantener una actitud abierta e investigadora a través del estudio personal.

En muchos casos acudimos a psicoterapia ante un sentido de urgencia o de "estar al límite", al coexistir la vivencia de agotamiento y el fracaso de los recursos personales. La realidad es que muchas veces esperamos a actuar cuando sentimos que el medio que habitamos se desploma, sin asumir y aceptar que tenemos un compromiso diario y de por vida con nosotros mismos.

Cada día se nos presenta el desafío de tener que soportarnos, tolerarnos, reconocernos, aceptarnos... y en definitiva, lidiar con todo aquello que amenaza nuestro equilibrio psíquico. Así que, honestamente, replanteémonos si atender y cuidar estos aspectos pertenece a una "segunda línea", tal y como califican últimamente algunos estamentos y medios de comunicación para nombrar a los dispositivos de intervención psicológica, que parecen cobrar impulso de forma tardía y en segundo plano ante la situación de emergencia. Una segunda línea reducida a enfocarse en el repertorio emocional, como si el sufrimiento humano dependiera de qué cuantía de sonrisas y lágrimas somos capaces de producir.

No es que crea que el complejo entramado de emociones y sentimientos del que disponemos carezca de importancia. Nada más lejos de la realidad. Al contrario, considero imprescindible conocer y detectar la presencia de diversos tipos de emociones y cómo estos se conectan 
entre sí, junto con otros procesos cognitivos y comportamentales, puesto que todo ello en su conjunto nos va a servir, a modo de termómetro, para identificar y traducir nuestro propio posicionamiento con respecto a la situación.

Más bien, lo que me llama la atención es la visión simplista y reduccionista con la que pretende el conjunto de nuestra nación mantenernos informados y contenidos ante la alarma, generando una atmósfera en la que muchas veces evitamos el llamar a las cosas por su nombre; creyendonos en la necesidad de utilizar metáforas bélicas para unirnos en rebaño y con afán patriótico contra la causa; $y$, por continuar con la metáfora, siendo bombardeados desde el adoctrinamiento con recomendaciones, consejos y perspectivas que amainen el ruido y calmen los ánimos. Porque está claro que intentar pensar por uno mismo, caer, aburrirse... trae consigo demasiados problemas.

Lo cierto es que vivimos en una sociedad cada vez más hiperestimulada e infantilizada, en la que las dificultades y problemáticas responden, en muchos casos, más a una cuestión de resistencia, negación y disociación ante la realidad, que a una cuestión de incompetencia e incapacidad. Lo que también me hace pensar en la pretensión de cosificación del individuo en nombre de la ciencia, a través de modelos descriptivos y estadísticos generalistas, y en el predominio de perspectivas biologicistas y economistas que continúan promoviendo un modelo de salud mental, en el que sólo parece tener acogida la enfermedad y el desorden como algo a lo hay que combatir y aplacar con inmediatez, sin pretender explorar con sentido crítico la subjetividad inherente.

Aquello de "la insoportable levedad del ser", nos lleva a la reflexión sobre si la existencia y el ser son más llevaderos desde una vivencia superficial y frívola; o bien asumiendo el peso que conlleva el compromiso y la responsabilidad con uno mismo y los demás.

Estos tiempos caracterizados por la sobresaturación, la inmediatez y lo gaseoso, nos hacen ser cada vez más miserables y desgraciados aunque creamos estar en una posición privilegiada. Nuestro funcionamiento se torna frenético y vertiginoso en aras de alcanzar ese imperativo absolutista llamado "felicidad", por el que deberíamos estar todos, de igual forma, sumidos en el disfrute y el goce compulsivo. Esto resulta cuanto menos paradójico, porque realizamos una gran inversión de tiempo y esfuerzo en ser productivos para alcanzar bienes materiales de diversa índole, en la tónica de lo políticamente correcto o de lo que está vigente. Pero en cuestión de economía emocional, tendemos a abandonarnos, porque lo cierto es que mantener relaciones afectivas de calidad implica altos niveles de autoconocimiento y trabajo personal, y estar preparado y dispuesto a asumir frustraciones, responsabilidad y trabajo duro. Algo que, en general, resulta demasiado caro y pesado. 
Así que sobrevivimos excesivamente alienados, anestesiados y limitados como para entrar en contacto con el conocimiento de una intimidad personal, y sin estar orientados a una realidad en la que a veces no existen certezas, ni garantías, ni tan si quiera el control de saberlo todo de forma anticipada. Para empezar, porque "se lleva" lo positivo y, en este sentido, las vacilaciones y las incertidumbres conllevan penalización. Y además, porque nuestra cotidianidad es vivida como un castigo, una cárcel, de la que debemos desconectar, huir y liberarnos, generalmente a través de un consumo voraz.

Están muy bien los aplausos y el festejo como acción comunitaria y como reconocimiento solidario ante la tremenda abnegación que está demostrando el sector sanitario; pero creo, verdaderamente, que lo que necesitamos en estos momentos, no sólo como urgencia, sino también como el resultado de algo que llevamos arrastrando hace mucho tiempo y en lo que deberíamos profundizar, es respeto, por uno mismo y por los demás. Y aquí, habría que señalarnos para adentro y ver qué es aquello en lo que podemos estar contribuyendo.

La enfermedad, el aislamiento y la estigmatización se abren paso en nuestra realidad cotidiana; esto no es nuevo. Es pronto para determinar la repercusión y las secuelas que van a dar lugar los tiempos que atravesamos. Os ofrecería recomendaciones, "tips", consejos, y demás "merchandising" y parafernalia propagandística para que fuerais felices, pero algunos iluminados se me han adelantado (sarcasmo). Además, creo en vuestra propia inventiva y capacidad creativa como para tomar vuestras propias decisiones al respecto. Os diría y os digo: "jacudid a los profesionales sanitarios oportunos!", "¡Asistid a terapia si existe la posibilidad!"; "pero no dejéis para mañana lo que importa hoy y todos los días."

Aprovechemos la parada obligatoria para escucharnos y resituarnos; para hacer introspección y balance sobre el punto hasta donde hemos llegado; para preguntarnos qué significa aquello de la autorrealización y ver de qué tenemos hambre y de qué se supone que nos estamos alimentando. Si preferimos acogernos a una posición pasiva de obediencia y que las decisiones difíciles las tome otro y si tan acostumbrados estamos a estar dominados desde la vergüenza y la culpa, que hemos hallado un lugar agridulce que habitar, presuntamente confortable. expresa. Este material es para uso científico y profesional exclusivamente y puede contener información clínica sensible. Los editores no se responsabilizan de los contenidos de los autores. Dirigir las consultas sobre derechos y autorizaciones a ceir@psicoterapiarelacional.es 